\title{
Research on the design of power generation system for 50MV wind farm
}

\author{
Zhang Mingsheng ${ }^{1}$, Wu Hesong*2, Wan Wenkui ${ }^{1}$, Feng Peilei ${ }^{3}$ \\ ${ }^{1}$ Kunming University of Science and Technology Oxbridge College Kunming, China \\ ${ }^{2}$ Diqing Grid Bureau, Yunnan Grid Corporation Limited, Diqing StateDiqing, China \\ ${ }^{3}$ School of Electrical and Information TechnologyYunnan Minzu University Kunming, China
}

\begin{abstract}
With the rapid development of the global economy, wind power generation has attracted wide attention all over the world. With the rapid development of all kinds of new energy in the world, wind power generation has a huge international market and broad prospects for development. Based on the actual situation of the local wind power generation project in a city, this paper analyses the feasibility of the wind power generation system in the local area. According to the type selection and arrangement of various types of wind motors, a reasonable electrical wiring part is designed. The research shows that wind power is of high comprehensive value. Wind power plants can be built in areas with suitable geographical conditions and sufficient wind energy. After the completion of the above power generation projects, the advantage of local wind energy resources will be fundamentally changed into economic advantage.
\end{abstract}

\section{Introduction}

With the rapid development of the global economy, the demand for electricity is gradually increasing in every country in the world. Clean energy, such as solar energy, wind energy, geothermal energy and so on, has been widely recognized and concerned all over the world[1]. At present, the core technology of wind power generation has come to a mature track. The wind power generation technology plays a vital role in the rapid development of the national economy. In the case of high global energy, this technology can also meet people's demand for new energy. Taking a city in China as an example, the city is one of the most developed areas of wind energy resources in China, and has good wind resources, which fully possesses the necessary conditions for developing wind energy[2]. The city carries out the planning and construction of the wind power plant project, which will vigorously promote the high speed development of the local wind power plant.

\section{Design of type selection and layout of wind turbine}

\subsection{Type selection of wind turbine generator set}

In recent years, the manufacturing technology of wind turbines has developed rapidly. The capacity of the single machine is getting bigger and larger, and the manufacturers of wind turbines have launched megawatts of wind turbines. For a specific wind farm, under the existing economic, technological and localization rates, the capacity of a single unit will be relatively high within a certain range. When selecting the capacity of the single machine, a capacity range suitable for this project should be determined. According to the situation of the wind resources in the region, a type of model with mature technology, good market performance, better economy and higher rate of domestically made is selected. The wind energy resource analysis results of wind farms show that the turbulence intensity of $30 \mathrm{~m}, 50 \mathrm{~m}, 60 \mathrm{~m}$ and $70 \mathrm{~m}$ is $0.13,0.11,0.11$ and 0.10 , respectively[3]. The design maximum wind speed of the pre installed hub height of the wind tower $(85 \mathrm{~m})$ for 50 years is $32.6 \mathrm{~m} / \mathrm{s}$. Considering the design wind speed and mountainous terrain of the wind farm, according to the design requirements of the wind turbine generator (GB 18451.1-2012), the fans of the wind farm should choose IIIB or more fans.

\subsection{Single machine capacity}

At present, there are three main levels of single machine capacity:megawatt unit.

The capacity of the single machine is between 1 and $2 \mathrm{MW}$, and the length of the blade is about $34 \sim 50 \mathrm{~m}$. The weight of the engine room is about $40 \sim 90$ tons, which mainly represents the $1.5 \mathrm{MW}$ and $2 \mathrm{MW}$ type wind turbines. This kind of unit is more mature in technology and suitable for the wind farm with convenient transportation. In the foreign wind power market, the 
share of the wind power market is large, and most of the wind farms are built in China at present. multi megawatt unit.

The components of this type of wind turbine are super long and overweight, and it is difficult to transport and hoisting. At present, there is a certain number of installation in the developed countries, mainly installed in the offshore wind farm, and has not been put into commercial operation on a large scale. According to the scope of the economic development site of this wind farm, the terrain geology and traffic conditions of the wind farm are combined. Considering the current situation of wind turbine market at home and abroad, and the installed capacity of wind farms in China, the capacity of the wind farm fan is $2 \mathrm{MW}$ or 2.2MW[4].

\subsection{Wind turbine layout}

\subsubsection{Principle of fan layout}

When a wind turbine is arranged in a wind farm, the following principles are followed[5]:

1) try to choose the regional fan with large density of wind energy.

According to the wind direction and wind energy rose chart, in the prevailing wind and wind direction, the unit is 5 times more than the diameter of the wind wheel.

Perpendicular to the prevailing wind direction, the unit is more than 3 times the diameter of the wind wheel.

2) carefully analyze the surface characteristics and avoid the arrangement of the wind turbines in areas with large turbulence intensity, such as the leeward slope of the leading wind direction.

Select the right spacing and row spacing to minimize the impact of the wake and make full use of the land resources.
3) minimize project investment, so that the length of roads and cables is shorter.

4) relatively centralized arrangement, easy to manage, reduce the line loss of electricity.

5) keep the distance between civil facilities and military facilities, especially the height of the fan, which is not higher than the limit of the navigation station. The wind power project does not interfere with the local production and life.

6) avoid the ecological strict control area.

\subsubsection{Layout scheme}

In the layout design of the wind turbine, the following steps are taken:

1) the application of the wind resource analysis software WindSim V5.1 based on CFD technology.

The digital topographic map (scale 1:10000) is combined with the wind direction and wind speed frequency distribution table of the wind farm special wind power tower \#3291.

The distribution map of wind resources atlas of the area of the wind farm is generated.

2) the optimization software WindFarmer v3.5.1 is designed by the wind farm widely used in the industry. According to the principle of wind turbine arrangement in the 5.2.1 section.

Considering the regional topography of the wind farm, the conditions of wind resources and boundary constraints, the optimal layout schemes for the two types of $2 \mathrm{MW}$ and $2.2 \mathrm{MW}$ models are formed respectively.

The wind turbine layout schemes for the distribution map of the wind resources map of $2 \mathrm{MW}$ and $2.2 \mathrm{MW}$ are shown in Figures 1 and Figure 2.

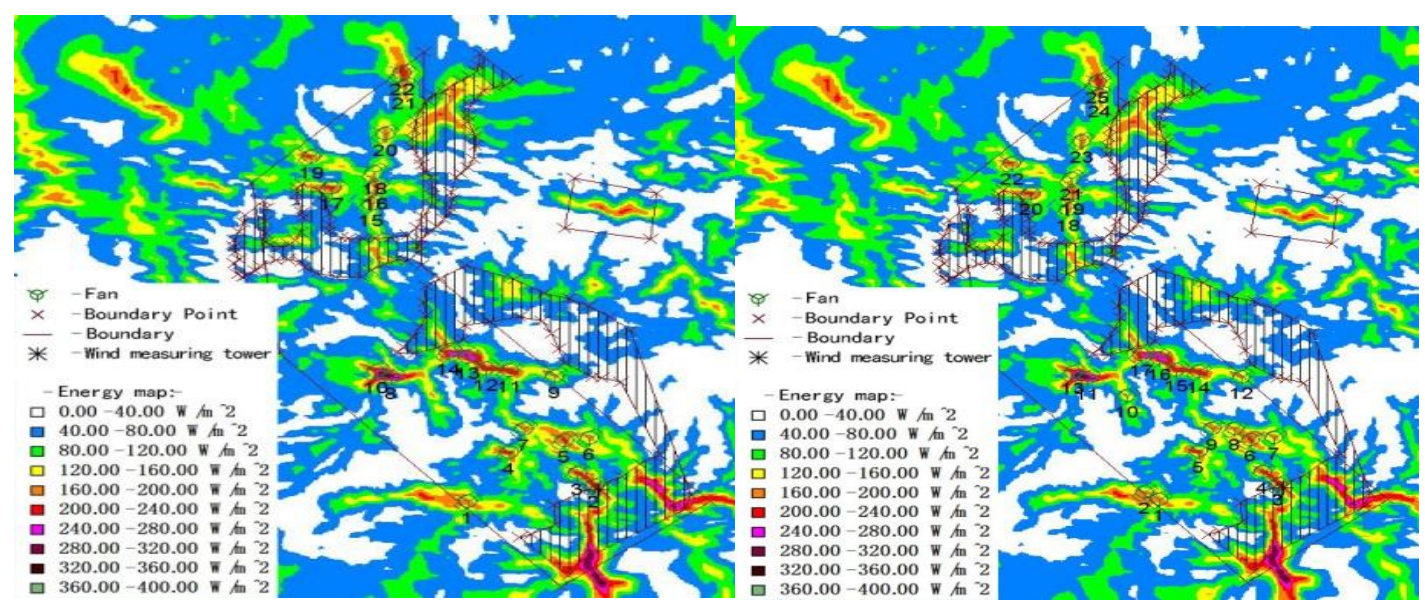

Figure $12 \mathrm{MW}$ fan arrangement sche me

3) according to the model WTG1 WTG5, the power generation is calculated using the fan layout scheme.
Figure 2 2.2MW fan arrangement scheme

A preliminary technical and economic comparison is made, and the results are shown in Table 1. 
Table 1 Comparison of the various schemes

\begin{tabular}{|c|c|c|c|c|c|}
\hline Projects & WTG1 & WTG2 & WTG3 & WTG4 & WTG5 \\
\hline $\begin{array}{c}\text { Total wind power generation without } \\
\text { wake effect (GWh) }\end{array}$ & 116.64 & 121.67 & 117.5 & 126.57 & 139.43 \\
\hline Wake loss & $3.15 \%$ & $3.04 \%$ & $2.91 \%$ & $2.93 \%$ & $3.12 \%$ \\
\hline $\begin{array}{c}\text { Total wind power generation capacity } \\
\text { considering wake effect (GWh) }\end{array}$ & 112.97 & 117.97 & 114.09 & 122.86 & 135.08 \\
\hline Actual power generation (GWh) & 79.08 & 82.58 & 79.86 & 92.15 & 101.31 \\
\hline Annual running hours (h) & 1581.6 & 1651.5 & 1597.2 & 1842.9 & 2026.2 \\
\hline $\begin{array}{c}\text { Initial investment in unit equipment } \\
\text { (ten thousand yuan) }\end{array}$ & 21000 & 20750 & 21000 & 22000 & 22000 \\
\hline Unit kilowatt cost (yuan /kWh) & 3.21 & 3.03 & 3.19 & 2.87 & 2.61 \\
\hline
\end{tabular}

The number of the fan and the installed capacity are the same. It is known from the above table .The five schemes selected are very close to and less than 4 of the wind turbine exhaust loss. In the actual year, the power generation and efficiency are optimal for scheme five, electricity consumption and average .The number of full hours in the year reached 101.31 GWh and 2026.2h, respectively. The cost of unit kilowatt is the lowest, and WTG5 is recommended at the present stage. The final layout of the fan should be determined by the microcosmic location.

\section{Electrical design part}

\subsection{Electrical primary part}

\subsubsection{Main electric wiring of wind farm}

1) combination mode of wind turbine and box substation

Fan - box change combination use "1 machine 1 change" unit connection, The connection mode has the advantages of low investment, less power loss, simple connection, convenient operation, any one box change or wind turbine failure, and no influence on other wind turbine's normal operation. This wind farm plans and installs 25 fans with a single capacity of $2 \mathrm{MW}$. The outlet voltage of the wind turbine is $0.69 \mathrm{kV}$, and the low voltage cable is buried to the low voltage side of the box type substation. The working current of the transformer's low voltage side flows is about 1674A. In order to reduce the loss, the box transformer is arranged near the $15 \mathrm{~m}$ radius of the wind turbine generator set. It is calculated that

the ZC-YJV22-0.6/1kV-3x240+1X120mm2 1kV low voltage power cable of 6 parallel laying is connected to the low voltage side of the box type transformer.

2) power line voltage selection

According to the loading scale of the wind farm and the voltage level of the access system, the power transmission and transformation system of the wind farm adopts the two step boost mode. According to the variable capacity of the box, the distance from the box to the $110 \mathrm{kV}$ booster station, the voltage level of the box type transformer and the voltage level of the collector line can be selected by two voltage levels, $10 \mathrm{kV}$ and $35 \mathrm{kV}$.

Due to the wide coverage of wind farms, according to the layout of wind farms, taking account of the voltage drop of $10 \mathrm{kV}$ collecting lines, each $5 \sim 6$ wind turbine consists of 1 collector units, which needs 5 circuits. This project has many problems, such as many circuits, large amount of work, long transmission distance, large voltage drop, large loss and so on, so this project does not consider this project.

The power line voltage level of this project is $35 \mathrm{kV}$. According to the situation of the cloth, considering the reliability of the power supply of the wind turbine, the whole wind farm is divided into 3 circuits, and each 8 9 typhoon machine is composed of a set unit. Compared with the $10 \mathrm{kV}$ voltage level, when adopting $35 \mathrm{kV}$ voltage level, the capacity of single loop transmission is larger, the line section of the conductor is smaller, the number of lines is less, the circuit corridor is solved well, and the voltage loss of $35 \mathrm{kV}$ conductor is small, and the power loss is also small.

3) power line scheme

The parallel connection mode is adopted in the high voltage $35 \mathrm{kV}$ side of the box type substation. Considering the layout of the wind turbine and the box type substation, the terrain and the trend of the $35 \mathrm{kV}$ collection line, In this paper, the whole wind farm is divided into 3 collection lines, each 8 9 typhoon machine constitutes a collection unit, and 25 wind generator box transformer groups are divided into 3 groups $(9,8,8$ sets respectively). The maximum capacity of the single set of collector lines is $18 \mathrm{MW}$.

\subsubsection{Electric main wiring of booster station}

The installed capacity of the wind farm is $50 \mathrm{MW}$, and 25 wind turbines with a single capacity of $2 \mathrm{MW}$ are first installed. The wind turbine by the box type substation up to $35 \mathrm{kV}$, the $35 \mathrm{kV}$ integrated circuit to the $110 \mathrm{kV}$ station, two times up to $110 \mathrm{kV}$ after access to $110 \mathrm{kV}$ east station, the overhead line length of about $3 \mathrm{~km}, 185 \mathrm{~mm} 2$ wire section.

The first selected model of this project is $2000 \mathrm{~kW}$ wind turbine. The power factor is +0.95 to -0.95 , and the number of units is 25 . When the main transformer capacity is selected, considering the fact that the load ratio of the wind farm is low, and the power factor of the wind turbine is about 1 , the main transformer equal to the power generation capacity of the wind farm can be selected. The main transformer in this period is a transformer with a total capacity of 50MVA. The connection mode of $35 \mathrm{kV}$ distribution device adopts single bus connection, and the connection mode of 
$110 \mathrm{kV}$ distribution device adopts line transformer group connection.

\subsubsection{Electric connection of station}

The voltage of this booster station is $380 / 220 \mathrm{~V}$, which is the direct grounding system of neutral point. 1 grounding transformer and station transformer are set up in the booster station. The transformer is selected as DKSC-1250/35-250/0.4, Zn, Yn11, $35+2$ x 2.5\%/0.4, $\mathrm{Uk}=6 \%$. In order to improve the reliability of power supply, the construction will be transformed into \#2 station after the end of the construction. At the same time, $1250 \mathrm{~kW}$ diesel generators are set up as the standby power supply for the accident. The station electricity uses the single parent segment connection, and the two bus bus is equipped with ATS automatic switching switch.

\subsubsection{Overvoltage protection}

1) direct lightning protection

The direct lightning protection protects the direct lightning protection of the $110 \mathrm{kV}$ lifting station and the electric equipment of the wind farm.

Lightning protection of electrical equipment and building in $110 \mathrm{kV}$ booster station

The $110 \mathrm{kV}$ booster station set up a $30 \mathrm{~m}$ high frame lightning rod to realize direct lightning protection for $110 \mathrm{kV}$ outdoor GIS, main transformer and SVG step-down transformer, and $110 \mathrm{kV}$ sent the line to set up the lightning conductor. The roof of the main control building and the living building is set up as a lightning protection.

Protection of direct lightning lightning in electric field of wind farm

The wind turbines are equipped with lightning protection devices. Wind turbines, towers and basic steel bars are all reliably connected to the grounding grid. The height of the box type substation is low, and it is within the protection range of the tower frame of the generator set.

2 ) Intrusion lightning protection of distribution device

Provisions in "grounding of AC electrical devices" DL/T621-1997 and "overvoltage protection and insulation coordination of AC electrical devices" $\mathrm{DL} / \mathrm{T} 620-1997$, the $110 \mathrm{kV}$ line is erected along the whole line to protect the overvoltage of the lightning invasion wave along the line. A group of Zinc Oxide metal arresters with no gaps are installed in the $110 \mathrm{kV}$ outlet, $35 \mathrm{kV}$ bus, main transformer neutral point and each transformer box high voltage side of the booster station, so as to protect the lightning invasion wave and other overvoltages.

\subsection{Electric part two}

\subsubsection{The setting of control room and relay room}

In this project, the main control room is set up in the $5.5 \mathrm{~m}$ layer of the control building. In the control room, there are wind farm computer monitoring system operator station, booster station computer monitoring system operator station, video security monitoring panel, microcomputer five workstation, engineer station, fire alarm monitoring screen and other equipment.

The layout in the second equipment room are main transformer protection panel, main transformer monitoring and control panel, $110 \mathrm{kV}$ line protection screen, $110 \mathrm{kV}$ line monitoring and control panel, fault recording panel, time synchronization time screen, watt hour meter screen, DC screen, UPS power supply panel, system automatic device screen and control communication screen and other equipment.

\subsubsection{Control system}

The project is designed according to the principle of "unattended, few people on duty" and run according to the mode of regular or unscheduled inspection by the operator. Through computer monitoring system, the centralized control and monitoring of wind turbines and $110 \mathrm{kV}$ booster stations in the main control room can be realized.

The computer monitoring and control system of this project includes the computer monitoring system of wind farm, the computer monitoring system of the booster station and the video security monitoring and control system. The computer monitoring and control system of the wind farm is responsible for monitoring and controlling the operation of the wind turbine and its $35 \mathrm{kV}$ booster equipment. The communication protocol of the monitoring system must be opened to the outside world. The computer monitoring system of booster station is responsible for centralized control of $110 \mathrm{kV}$ line, main transformer, $35 \mathrm{kV}$ line, $35 \mathrm{kV}$ reactive power compensation equipment, $35 \mathrm{kV}$ station transformer and public equipment. The video security system is used to monitor the field operation of the main equipment in the boost station. All computer monitoring systems should be considered as a whole and communication protocols are open to each other.

\subsubsection{Relay protection and automatic device}

The configuration of relay protection is according to GB/T 14285-2006 "technical regulations of relay protection and safety automatic device", southern Power Grid Corp Q/CSG10012-2005 "technical guidelines for urban distribution network of China Southern Power Grid" and the requirements of "twenty-five key requirements to prevent major accidents in electric power production" requirements for the implementation of relay protection.

The optical fiber current differential protection is used as the main protection for the $110 \mathrm{kV}$ line. The $35 \mathrm{kV}$ bus is configured as the bus differential protection. The main protection of the main transformer uses the current longitudinal differential protection as the main protection. The relay protection device of the wind turbine is provided by the fan manufacturer. The 
definition of the protection exit can be acted on the outlet circuit breaker and signal of the wind turbine.

\section{Summary}

At present, the country attaches great importance to the development of new energy. Renewable energy, such as wind energy and solar energy, will be the key to the development of new energy in the future. Wind energy is known as one of the most developed new green energy sources in twenty-first Century. The area is rich in wind energy reserves and the construction of wind farms can benefit the development of local wind power resources. The total installed capacity of the wind farm is $50 \mathrm{MW}$. After the completion of the project, instead of traditional power supply, the emission of various air pollutants, such as sulfur dioxide ( $\mathrm{SO} 2)$, carbon monoxide (CO) and carbon dioxide $(\mathrm{CO} 2)$, can be reduced every year. It is of great significance to promote the development of local wind power, alleviate the pressure of environmental protection, promote the green development of the local economy, and promote the transformation and upgrading of the regional economy. It has a very strong demonstration effect.

\section{References}

1. Qidehua The relationship between rural energy and development and utilization "Farm Technology Quarterly",2015 (2)

2. Shen Ling Study on the endowment and exploitation of wind energy resources in Jiangsu coast "Resource development and city, 2010,26 (1): 48-51

3. Hua Fan Research on $49.5 \mathrm{MW}$ wind farm project feasibility of Hohhot City West waves Tianjin University, 2012

4. Zhou Huijuan Study on type selection of wind turbine in the construction of thirty-six Bay wind farm , 2015 (12): 94-97

5. Qi Hong Optimization design of wind farms considering the distribution of wind energy resources "North China Electric Power University", 2014 